\title{
Effects of high power ultrasound on all-E- $\beta$-carotene, newly formed compounds analysis by ultra-high-performance liquid chromatography-tandem mass spectrometry
}

\author{
Michel Carail ${ }^{\mathrm{a}, \mathrm{b}}$, Anne-Sylvie Fabiano-Tixier ${ }^{\mathrm{b}, \mathrm{a}}$, Alice Meullemiestre ${ }^{\mathrm{b}, \mathrm{a}}$, Farid Chemat ${ }^{\mathrm{b}, \mathrm{a}}$, \\ Catherine Caris-Veyrat ${ }^{\mathrm{a}, \mathrm{b}, *}$ \\ a INRA, UMR408 Sécurité et Qualité des Produits d'Origine Végétale, F-84000 Avignon, France \\ ${ }^{\mathrm{b}}$ Université d'Avignon et des Pays du Vaucluse, UMR408 Sécurité et Qualité des Produits d'Origine Végétale, F-84000 Avignon, France
}

\begin{abstract}
A B S T R A C T
To study effects of high power ultrasound treatment $(20 \mathrm{kHz})$ on $\beta$-carotene degradation, a second-order central composite design (CCD) was performed to investigate maximum $\beta$-carotene loss with three independent factors (ultrasonic intensity, sonication time, and temperature). Results based on variance analysis and Pareto chart have shown that sonication time is the most important factor, followed by ultrasonic intensity level. The evolved degradation products have been tentatively identified using ultra high performance liquid chromatography coupled to both diode array detector and a mass spectrometer (UHPLC-DAD-MS). The main degradation products, tentatively identified, are three $Z$-isomers of $\beta$-carotene and seven $\beta$-apo-carotenals/ones. Hypothesis on the degradation mechanism of carotenoids are presented.
\end{abstract}

Keywords:

$\beta$-Carotene

Isomerization

Degradation

UHPLC

Mass spectrometry

\section{Introduction}

The main aims of new food processing technologies are to reduce processing time, save energy, and improve the shelf life and quality of food products. Thermal (radio frequency and microwave heating), vacuum cooling, high pressure, ultrasound processing, and pulsed electric field processes are novel food processing technologies which have the potential to produce high-quality, safe food products [1]. However, current limitations related to high investment costs, full control of variables associated with the process, lack of regulatory approval, and consumer acceptance have delayed wider implementation of these

Abbreviations: MTBE, methyl-tert-butyl ether; THF, tetrahydrofuran; HPLC, high-performance liquid chromatography; UHPLC, ultra-high-performance liquid chromatography; DAD, diode array detector; MS, mass spectrometer; APCI, atmospheric pressure chemical ionization; CCD, central composite design; $\mathrm{CCI}$, central composite inscribed design; ANOVA, analysis of variance; ROS, reactive oxygen species.

* Corresponding author at: UMR408 Sécurité et Qualité des Produits d'Origine Végétale, INRA Centre de Recherche PACA, 228 route de l'Aérodrome CS 40509, Domaine Saint Paul, Site Agroparc, 84914 Avignon Cedex 9, France. Tel.: +33 43272 24 89; fax: +33432722492.

E-mail address: catherine.caris@avignon.inra.fr (C. Caris-Veyrat). technologies at the industrial scale. Ultrasound is well known to have a significant reduction on the multiple factors necessary to create a shelf-stable food product. Advantages of using ultrasound for food processing are numerous and include effective mixing and micro-mixing, faster energy transfer, reduced thermal and concentration gradients, reduced temperature, and process step elimination $[2,3]$.

Several studies have been carried out on the degradation effects of ultrasound power on vegetables [4], on microorganisms [5], enzymes [6], and food components such as proteins [7], starch [8], and edible oils $[9,10]$. Ultrasound treatment can be responsible for the aggregation and decomposition of polysaccharides [11], [12]. Regarding phytochemicals, depending on solvent, polyphenol degradation can also be caused by ultrasonic treatment (for instance [13-15]). However, there is limited information on the effect of ultrasound treatment on carotenoids, which is one of the most important class of natural pigments and which present nutritional interest. Carotenoids are chemically sensitive to degradation due to their poly-isoprenoid structure conferring a long chain of conjugated double bonds. Zhao et al. [16] have found that all-E-astaxanthin submitted to ultrasound treatment in a model system is degraded to unidentified colourless compounds. Sun et al. [17] have shown that the temperature and nature of solvents 
Version définitive du manuscrit publiée dans / Final version of the manuscript published in :

Ultrasonics Sonochemistry (2015), Vol. 26, p. 200-209, DOI: 10.1016/j.ultsonch.2015.04.003

Journal homepage : http://www.elsevier.com/locate/ultson

are determining factors in the degradation of $\beta$-carotene submitted to ultrasound treatment. Moreover, they identified that liquid height, ultrasonic intensity, and duty cycle of ultrasound exposure affected the rate of degradation but did not change the nature of $\beta$-carotene degradation products. These degradation compounds generated by ultrasound were tentatively identified as isomers (15-Z- $\beta$-carotene, di-Z- $\beta$-carotene) and other compounds with carbonyl functional groups. However, the carotenoid degradation mechanism under ultrasound treatment remains unclear. Taken together, these studies provide evidence to support the hypothesis that the biophysical impacts of ultrasound can be characterized as thermal, cavitation, and direct effects. Thus, the degradation mechanisms of molecules submitted to ultrasound may be complex due to each effect independently, as well as the interaction of these three types of effects. Cavitation produces mainly nonthermal effect. Furthermore, the collapse of cavitation bubbles are known to produce a variety of free species and induce local shock waves, while the oscillation of cavitation bubbles may be responsible for hydrodynamic shearing stress.

The aim of this work was to study the influence of important ultrasound parameters (ultrasonic intensity, sonication time, and temperature) on $\beta$-carotene stability in two organic solvents (hexane and tetrahydrofuran) and water under different atmospheres. $\beta$-Carotene is liposoluble, so in water it is under crystalline form, thus mimicking the storage form of carotenoids in the chromoplast microstructure of some fruits and vegetables [18]. After a series of initial experiments using different solvents and atmospheres, we selected one model system to conduct the remainder of the analyses. This model system allowed us to determine the most important parameters, both individually, and in combination, to generate the maximum degradation of $\beta$-carotene. Finally, UHPLC-DAD coupled with a MS using APCI ionization was employed to characterize and to tentatively identify the newly formed compounds derived from $\beta$-carotene during the ultrasound treatment.

\section{Material and methods}

\subsection{Chemicals}

$\beta$-Carotene standard (95-99\% purity) was purchased from Sigma-Aldrich Corp. St. Louis, MO, USA. Methyl-tert-butyl ether (MTBE), hexane, and tetrahydrofuran (THF) HPLC grade were purchased from Thermo Fisher Scientific Inc., MA, USA. THF was further purified by elution on activated basic alumina to remove peroxides. Aluminium oxide, activated basic $50-200 \mu \mathrm{m}$ for column chromatography, Brockmann activity I, was purchased from Acros Organics 1, Reagent Lane, Fair Lawn, NJ, USA. MilliQ distilled water was obtained using a Millipore ${ }^{\circledR}$ QPak system (Millipore Corporation, Bedford, USA). Hexane, THF, and water were used as solvents for ultrasound treatment. MTBE was used for extraction of $\beta$-carotene from water. All additional solvents (methanol, dichloromethane, acetone, acetonitrile) used for analysis were purchased from Thermo Fisher Scientific Inc and classified as high-performance liquid chromatography (HPLC) grade.

\subsection{Instrumentation}

\subsubsection{Ultrasonic reactor}

The experimental setup used to perform sonication of the solutions of $\beta$-carotene is described in Fig. 1. The ultrasonic transmitter (Vibracell 75186, $20 \mathrm{kHz}$ ) was connected to a probe (probe tip diameter of $6 \mathrm{~mm}$ and length of $108 \mathrm{~mm}$ ) with a total supplied power input of $130 \mathrm{~W}$. The ultrasonic intensity, defined as ultrasonic power dissipation per surface unit, varied in the range $10.8-88.7 \mathrm{~W} \mathrm{~cm}^{-2}$. All experiments were carried out in the same reactor. The double layer reactor $(3 \times 6 \times 10 \mathrm{~cm})$ allowed water to circulate in order to control the medium temperature. The cap was equipped with three ground glass tubes to receive a condenser, a gas adding system, and the ultrasound and temperature probes which were placed in the same glass tubes and connected

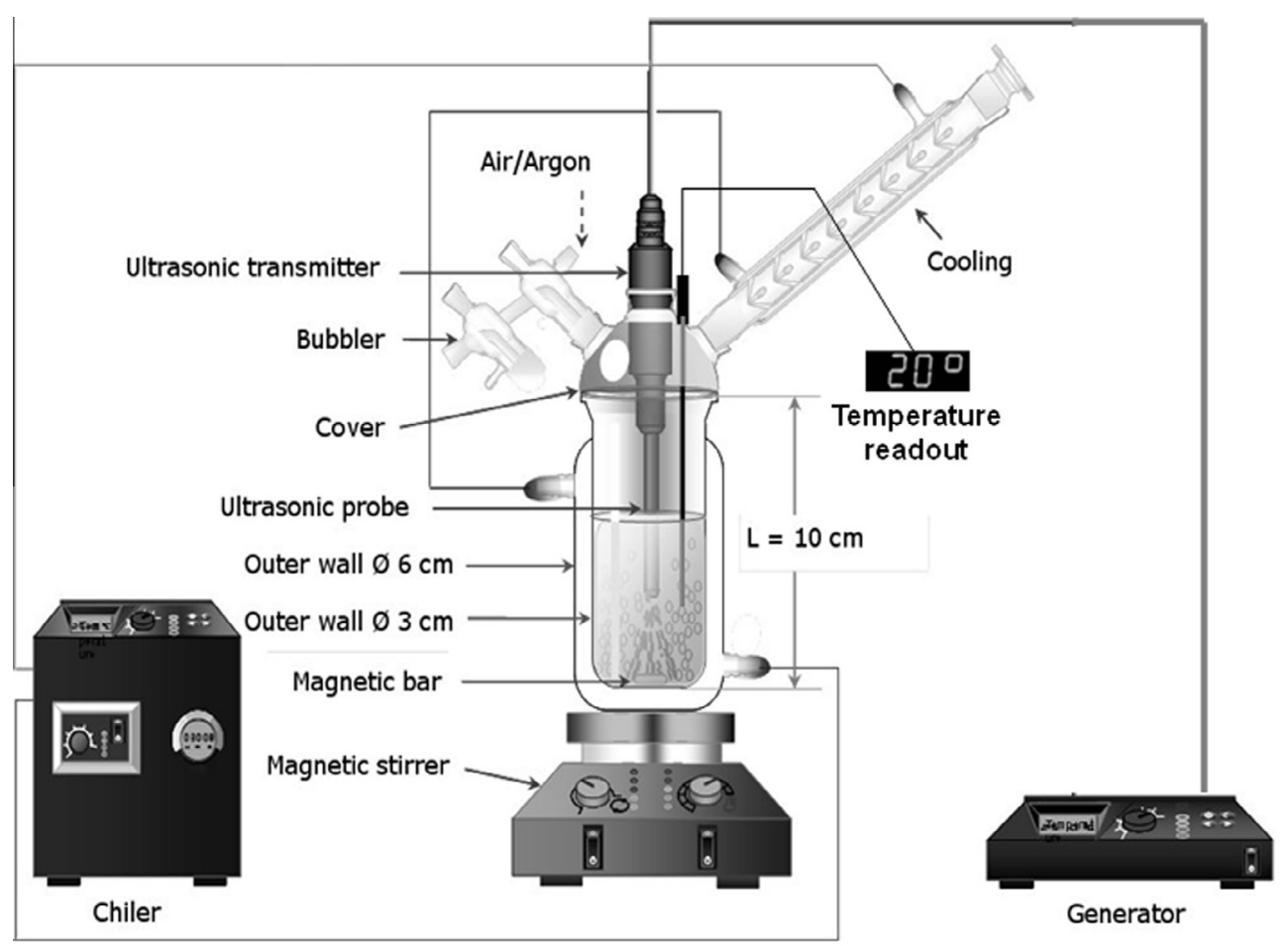

Fig. 1. Scheme of the ultrasonic reactor. 
to the tube using a rubber joint. The experiments were conducted with an aluminium sheet covering the reactor to ensure there was no light during ultrasound treatment.

\subsubsection{Spectrophotometer}

Spectra were recorded on a Hewlett-Packard 8453 diode-array spectrophotometer equipped with a quartz cell.

\subsection{Experimental setup}

\subsubsection{Ultrasound treatment}

The solvent was saturated with the gas specified (air or argon) for $5 \mathrm{~min}$ with a micro bubble dispenser, then $1 \mathrm{mg}$ of crystalline $\beta$-carotene standard was placed in the reactor with $100 \mathrm{~mL}$ of solvent (water, hexane or THF). To dissolve carotenoids, hexane and THF are among the most efficient solvents. Chlorinated solvents are also very efficient, as previously noted by Sun et al. [17] who have demonstrated that chlorinated solvents degrade carotenoids under ultrasound treatment. During sonication, the dead volume was kept under the desired atmosphere by a slow stream of gas controlled with a bubbler plugging the exit end. The ultrasound probe was submerged to a depth of $6 \mathrm{~cm}$ from the reactor bottom. Energy input was controlled by setting the amplitude of the sonication probe, and time was started once the set temperature was reached in the reactor. Throughout sonication, a magnetic stir bar was used to ensure uniform absorption of ultrasonic energy and medium homogeneity. Considering the actual input power is converted to heat which is dissipated in the medium, the actual ultrasound power was determined by calorimetry, calculated as shown in the equation (1) below.

$P=m \cdot C p \cdot \frac{d T}{d t}$

where $C p$ is the heat capacity of the solvent at constant pressure $\left(\mathrm{J} \mathrm{g}^{-1} \mathrm{~K}^{-1}\right), m$ is the mass of solvent $(\mathrm{g})$ and $d T / d t$ is the temperature rise per second. The consequent ultrasonic intensity (UI) was calculated for the ultrasonic probe using the calculated power (from Eq. (1)) as shown in the equation (2).

$U I=\frac{4 P}{\pi D^{2}}$

where $U I$ is the ultrasonic intensity $\left(\mathrm{W} \mathrm{cm}^{-2}\right), P$ is the ultrasound power (W) as calculated by the Eq. (1), and $D$ is the internal diameter $(\mathrm{cm})$ at the tip of the probe. The temperatures in the beginning and at the end of ultrasound treatment for each solvent were assessed for further comparison.

Various reference solutions were tested using the same parameters without ultrasound treatment. Residual $\beta$-carotene concentration was evaluated by spectrophotometric measurement at $452 \mathrm{~nm}$. When water was used as the solvent, $\beta$-carotene was first extracted with MTBE before the spectrophotometric reading.

2.3.1.1. Experimental design experiments. Preliminary tests were performed in triplicate to measure the combined effect of the different solvents under air or argon gas on the stability of $\beta$-carotene treated with ultrasound. Time of sonication, temperature, and

Table 1

Coded levels and independent variables employed in central composite design.

\begin{tabular}{lllllll}
\hline Independent variables & Symbol & \multicolumn{3}{l}{ Coded levels } & & \\
\cline { 3 - 7 } & & $-\alpha$ & -1 & 0 & +1 & $+\alpha$ \\
\hline Ultrasonic intensity $\left(\mathrm{W} \mathrm{cm}^{-2}\right)$ & $\mathrm{A}$ & 10.8 & 26.6 & 49.8 & 72.9 & 88.7 \\
Temperature $\left({ }^{\circ} \mathrm{C}\right)$ & $\mathrm{B}$ & 5 & 12 & 22.5 & 33 & 40 \\
Sonication time $(\mathrm{min})$ & $\mathrm{C}$ & 1 & 2.8 & 5.4 & 8 & 10
\end{tabular}

ultrasonic intensity were set to $10 \mathrm{~min}, 10^{\circ} \mathrm{C}$, and amplitude of $100 \%$ of sonication intensity, respectively. Results were statistically compared using the one-way ANOVA function in $R$, with each combination of atmosphere (air, argon), sonication (yes, no), and solvent (water, hexane, tetrahydrofuran) serving as a separate group, and \% $\beta$-carotene as the dependent variable. Post-hoc comparisons were made using Tukey's honest significant difference, with a $P$ value $<0.05$ considered significant. Water + air gave the most interesting preliminary results, and thus this combination was used in the remaining experiments. Extrinsic parameters of temperature $\left(5-40^{\circ} \mathrm{C}\right)$, ultrasonic intensity $\left(10.8-88.7 \mathrm{~W} \mathrm{~cm}^{-2}\right)$ and treatment time (1-10 $\mathrm{min})$, of the final model experiments were varied in accordance with the values predicted by the preliminary experiments.

\subsubsection{Extraction and calculation procedure}

$\beta$-Carotene treated by ultrasound was fully extracted from water with four $25 \mathrm{~mL}$ extractions of MTBE. The organic solvent was pooled and evaporated under vacuum, and the dry residue was dissolved again in $100 \mathrm{~mL}$ of MTBE. An aliquot was diluted two fold with MTBE and the absorbance was measured at $452 \mathrm{~nm}$. The concentration of total $\beta$-carotene after extraction was calculated using Beer-Lambert's law, and expressed in milligrams of $\beta$-carotene per litre of MTBE.

\subsubsection{UHPLC-DAD-MS analysis}

UHPLC-DAD-MS analyses of $\beta$-carotene solutions treated by ultrasound were performed using an ACQUITY UPLC ${ }^{\circledR}$ system (Waters Corp., Milford, MA, USA) linked simultaneously to both a DAD diode array detector 200-800 nm (Waters, Milford, MA, USA) and a Bruker Daltonics HCT Ultra Ion Trap mass spectrometer equipped with an atmospheric pressure chemical ionization tandem mass spectrometry (APCI) source operated in positive ion mode. Compass ${ }^{\mathrm{TM}}$ software (Bruker Daltonics, Bremen, Germany) was used for mass spectrometric instrument control and data processing. An Acquity C18 Waters ${ }^{\circledR}$ HSS T3 column (length: $150 \mathrm{~mm}$; internal diameter $2.1 \mathrm{~mm}$; particle size: $1.8 \mu \mathrm{m}$ ) was used for the separation. A volume of $10 \mu \mathrm{L}$ of each sample was injected. To perform a global separation of the degradation compounds from $\beta$-carotene, the column was kept at $45^{\circ} \mathrm{C}$. The mobile phase consisted of water (containing $0.02 \mathrm{M}$ ammonium formate) (A) and methanol $(0.02 \% \mathrm{w} / \mathrm{v} \mathrm{HCOOH})(\mathrm{B})$. The mobile phase conditions were as follows: $50 \% \mathrm{~B}$ held for $2 \mathrm{~min}$, followed by a linear gradient to $100 \%$ B over $8 \mathrm{~min}$ and held at $100 \%$ B for $30 \mathrm{~min}$. Total run time was $40 \mathrm{~min}$, with a constant flow of $0.4 \mathrm{~mL}$ per min. The DAD detector wavelength range was set to $220-600 \mathrm{~nm}$ with 20 points $\mathrm{s}^{-1}$ acquisition rate.

To perform signal acquisitions, mass spectrometer Esquire ${ }^{\mathrm{TM}}$ tune detector was set using the following parameters:

capillary $=-2000 \mathrm{~V}$, range $=100-800 \mathrm{Da}$, corona $=3200 \mathrm{nA}$, vaporizer $=350^{\circ} \mathrm{C}$, nebulizer $=50 \mathrm{psi}$, dry gas $=5.00 \mathrm{~L} \mathrm{~min}^{-1}$, target mass $=400 \mathrm{Da}$, compound stability $=100 \%$,

trap drive level $=100 \%$, optimize $=$ "Wide"

Mass spectra were collected by scanning the mass range from 200 to $800 \mathrm{~m} / \mathrm{z}$. The degradation products were tentatively identified according to their predominant protonated parent ion $[\mathrm{M}+\mathrm{H}]^{+}$ and UV/visible spectra by comparing with literature data, when available. Spectra produced after MS fragmentation was further used to tentatively identify new products.

\subsection{Experimental design}

Box-Wilson design, also called central composite design (CCD), was used to obtain maximal information about the degradation 
Version définitive du manuscrit publiée dans / Final version of the manuscript published in :

Ultrasonics Sonochemistry (2015), Vol. 26, p. 200-209, DOI: 10.1016/j.ultsonch.2015.04.003

Journal homepage : http://www.elsevier.com/locate/ultson

Table 2

Central composite design (CCD) with experimental values of all-trans- $\beta$-carotene degradation.

\begin{tabular}{|c|c|c|c|c|c|}
\hline \multirow[t]{2}{*}{ Trial $N$} & \multirow{2}{*}{$\begin{array}{l}X_{1} \\
\text { Ultrasonic intensity }\left(\mathrm{W} \mathrm{cm}^{-2}\right)\end{array}$} & \multirow{2}{*}{$\begin{array}{l}X_{2} \\
\text { Temperature }\left({ }^{\circ} \mathrm{C}\right)\end{array}$} & \multirow{2}{*}{$\begin{array}{l}X_{3} \\
\text { Sonication time }(\mathrm{min})\end{array}$} & \multicolumn{2}{|c|}{$Y$ (degradation rate) } \\
\hline & & & & Experimental (\%) & Predicted (\%) \\
\hline 1 & +1 & +1 & +1 & 19.9 & 22.4 \\
\hline 2 & 0 & 0 & 0 & 15.1 & 15.4 \\
\hline 3 & 0 & 0 & 0 & 15.5 & 15.4 \\
\hline 4 & 0 & 0 & $+\alpha$ & 34.9 & 30.9 \\
\hline 5 & 0 & $-\alpha$ & 0 & 13.8 & 14.0 \\
\hline 6 & -1 & +1 & -1 & 12.5 & 9.5 \\
\hline 7 & -1 & -1 & -1 & 9.1 & 6.9 \\
\hline 8 & 0 & $+\alpha$ & 0 & 9.5 & 9.0 \\
\hline 9 & -1 & -1 & +1 & 17.5 & 18.3 \\
\hline 10 & +1 & -1 & +1 & 27.8 & 31.1 \\
\hline 11 & 0 & 0 & $-\alpha$ & 3.8 & 8.3 \\
\hline 12 & 0 & 0 & 0 & 15.3 & 15.4 \\
\hline 13 & +1 & -1 & -1 & 10.1 & 8.2 \\
\hline 14 & +1 & +1 & -1 & 8.8 & 8.3 \\
\hline 15 & $-\alpha$ & 0 & 0 & 7.1 & 8.5 \\
\hline 16 & -1 & +1 & +1 & 10.1 & 12.2 \\
\hline 17 & 0 & 0 & 0 & 15.1 & 15.4 \\
\hline 18 & $+\alpha$ & 0 & 0 & 20.2 & 18.2 \\
\hline 19 & 0 & 0 & 0 & 15.5 & 15.4 \\
\hline 20 & 0 & 0 & 0 & 15.8 & 15.4 \\
\hline
\end{tabular}

$\square$ Without Ultrasound

$\square$ Ultrasound treated

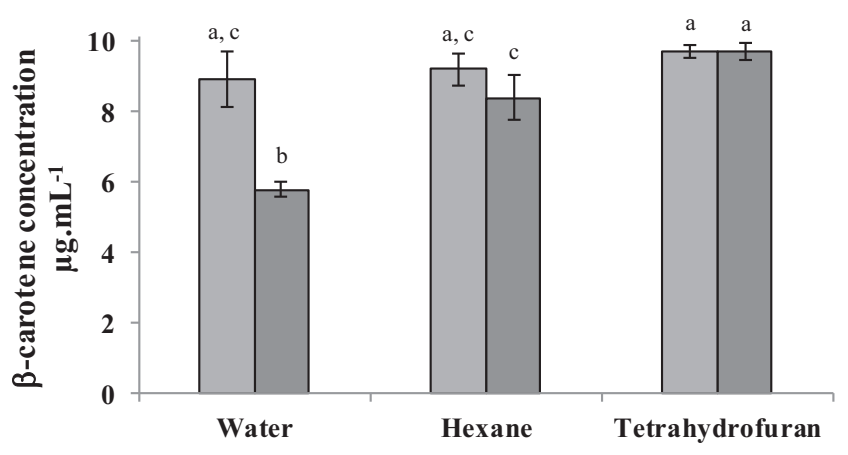

Fig. 2. Solvent and air atmosphere effect on the stability of all- $E$ - $\beta$-carotene under ultrasound treatment $(n=3)$. Different letters denote statistically significant differences $(P<0.05)$.

process from a minimal number of experiments. The type of CCD used in this study was Central Composite Inscribed design (CCI). This experimental design has the advantage of being rotatable, to determine the conditions that cause the greatest loss of $\beta$-carotene. Three independent factors (i.e. ultrasonic intensity (A), temperature (B), and sonication time (C)) were evaluated, as well as interactions between these variables. The CCD was comprised of a twolevel full factorial design (coded \pm 1 ), superimposed by centre points (coded 0 ) and "star points" (coded $\pm \alpha$ ).

A CCD could be compared to a virtual cube, with each axis of the cube corresponding to one variable in the model. In this study, the CDD points describe a spherical volume around the factorial cube. The group of "star points" was placed on variable axes at a distance $\alpha$ from the centre, allowing spherical symmetry. This orientation established new extremes for the low and high parameters of the factors involved. These extreme points provided an estimation of the curvature of the model. The resulting value was a function of properties desired for the design and depended upon the number of experiments involved in the model.

Preliminary experiments allowed us to determine the variables implied in the model at five separated coded levels: $-\alpha(=-1.68)$, $-1,0,+1,+\alpha(=+1.68)$. The natural values and coded levels used in this multivariate analysis are presented in Tables 1 and 2 . These values were used in a total of 20 experiments (including six replications at the centre point to evaluate experimental error measurement), and randomized to avoid effects of extraneous error. Variables were coded according to the following equation (3), where $X_{\mathrm{i}}$ is the coded value, $x_{\mathrm{i}}$ is the real value of one variable, $\bar{X}_{i}$ is the real value of a variable at the centre point, and $\Delta x_{\mathrm{i}}$ the step change:

$X_{i}=\frac{x_{i}-\bar{x}_{l}}{\Delta x_{i}}$

For predicting the optimal point, the experimental results were fitted to the second-order polynomial model equation (4):

$$
\begin{gathered}
Y=\beta_{0}+\sum_{i=1}^{n} \beta_{i} X_{i}+\sum_{i=1}^{n} \beta_{i i} X_{i}^{2}+\sum_{i=1}^{n-1} \sum_{j=2}^{n} \beta_{i j} X_{i} X_{j} \\
j>i
\end{gathered}
$$

where $Y$ is the response variable of degradation of $\beta$-carotene, $\beta_{0}$ is the average response obtained for replicated experiments of the $\mathrm{CCD}, \beta_{i}, \beta_{i i}, \beta_{i j}$, are the linear, quadratic, and cross products effects, respectively, $X_{i}$ and $X_{j}$ are the independent coded variables.

The results were analysed using the Statgraphics $X V^{\circledR}$ software, developed by Statpoint Technologies, Inc. 560 Broadview Avenue, Suite 201Warrenton, Virginia, USA. In order to test the model significance and suitability, analysis of variance (ANOVA) at a $95 \%$ confidence level was then carried out for each response variable. The $F$-value is the ratio of mean square error to the pure error obtained from the replicates at design centre, and the $P$-value $<0.05$ is considered significant.

\section{Results}

\subsection{Preliminary experiments}

\subsubsection{Influence of solvent and atmosphere on the stability of $\beta$ - carotene}

The combined effects of different solvents on the concentration of $\beta$-carotene after treatment by ultrasound under an atmosphere of air or argon are shown in Figs. 2 and 3, respectively. With air atmosphere (Fig. 2), we observed significant differences in $\beta$-carotene levels between ultrasound treated vs. non-treated samples in water, but not hexane or tetrahydrofuran. Comparison between the 3 solvents treated with ultrasound revealed a 
$\square$ Without ultrasound

$\square$ Ultrasound Treated อే $\mathbf{0}$
0

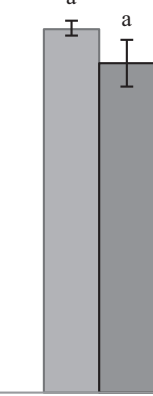

Water

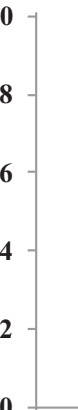

$-1$

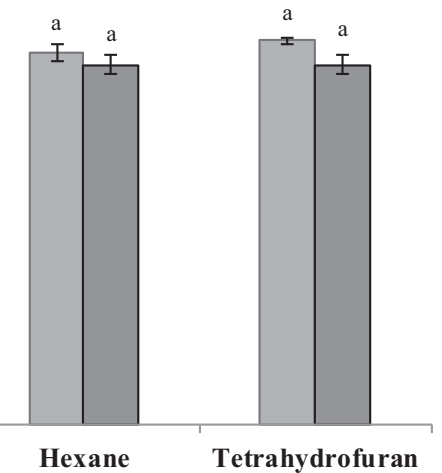

Fig. 3. Solvent and argon atmosphere effects on the stability of all-E- $\beta$-carotene under ultrasound treatment $(n=3)$. Different letters denote statistically significant differences $(P<0.05)$.

stepwise increase in degradation with maximum degradation observed for water $>$ hexane $>$ tetrahydrofuran. In contrast, under an atmosphere of argon (Fig. 3), there was no significant difference between ultrasound treated $v s$. non-treated samples, nor between solvents treated with ultrasound. Finally, with water the degradation during sonication was significantly greater with air as atmosphere as compared to argon $(P<0.05)$. It has been previously demonstrated that water sonolysis leads to reactive oxygen species (ROS) formation (Fig. 4) such as hydroxyl radicals $\left(\mathrm{OH}^{-}\right)$and hydrogen peroxyl radicals $\left(\mathrm{HO}_{2}\right)$ [19]. These species are highly reactive and could easily react with $\beta$-carotene. Because of the results of these preliminary experiments, and because we want to achieve the maximum degradation of $\beta$-carotene, we decided to perform the central composite design model experiments with water as our solvent and air as our atmosphere.

\subsection{Central composite design results}

The coded values of independent variables and the responses obtained in the multivariate study for each experiment are shown in Tables 1 and 2 . The degradation rate varied widely with the parameter settings of the ultrasonicator (from 3.8\% to 34.9\%). The maximum loss rate was observed in run number $4(Y=34.9 \%)$, for medium values of ultrasonic intensity and temperature (49.8 $\mathrm{W} \mathrm{cm}^{-2}$ and $22.5^{\circ} \mathrm{C}$, respectively) and highest sonication time $(10 \mathrm{~min})$. In contrast, the minimum loss rate was achieved in run number $11(Y=3.8 \%)$ with the same ultrasonic intensity and temperature conditions and the lowest sonication time (1 min). An analysis of variance (ANOVA) was carried out in order to test the model significance and suitability. Statistical results are provided in Table 3. Our results demonstrate that three effects, ultrasonic intensity, sonication time and their combination (i.e. A, $C$ and $A C$ ) significantly impact $\beta$-carotene degradation. For the

\begin{tabular}{|c|c|c|}
\hline $\mathrm{H}_{2} \mathrm{O}$ & 1)) & $\mathrm{H}^{\cdot}+\mathrm{OH}^{\cdot}$ \\
\hline $\mathrm{H}^{\cdot}+\mathrm{O}_{2}$ & & $\mathrm{HO}_{2} \cdot$ \\
\hline $\mathrm{HO}_{2} \cdot+\mathrm{HO}_{2}$ & & $\mathrm{H}_{2} \mathrm{O}_{2}+\mathrm{O}_{2}$ \\
\hline $\mathrm{OH} \cdot+\mathrm{OH}^{\cdot}$ & & $\mathrm{H}_{2} \mathrm{O}_{2}$ \\
\hline $\mathrm{H}_{2} \mathrm{O}_{2}$ & )) & $\mathrm{OH} \cdot+\mathrm{OH}$ \\
\hline
\end{tabular}

Fig. 4. Sonolysis of water.))) = ultrasound fitted model, the $R^{2}$ value indicates that a remarkable $90.37 \%$ of the sample variation for $\beta$-carotene degradation can be attributed to the independent variable, while only $9.63 \%$ of the total variation cannot be explained by the regression model. The value of the adjusted determination coefficient $\left(R_{\mathrm{a}}^{2}=81.71 \%\right)$ is also very high, showing a high significance of the model. A Pareto chart of standardized effects (Fig. 5) was carried out in order to determine significant effects of all variables (linear, quadratic, and interactions between variables). The length of each bar is proportional to the absolute magnitude of the estimated effect coefficients. Linear positive effects of the two key variables (A and $C$ ) appear to be highly significant, as is the interaction between $A$ and $C$. The negative effect of the $B$ variable indicates that $\beta$-carotene loss decreased with increasing temperature.

The experimental data set built after running 20 trials allowed us to fit all the responses as a function of temperature, ultrasonic intensity, and sonication time. The second-order polynomial equation (5) of the response surface obtained is as follows:

$$
\begin{aligned}
\mathrm{Y}= & -4.6761+0.0563 . \mathrm{A}+0.9928 . \mathrm{B}-0.2334 . \mathrm{C}-0.0013 . \mathrm{A}^{2} \\
& -0.00263 . \mathrm{AB}+0.0475 . \mathrm{AC}-0.0127 . \mathrm{B}^{2}-0.0801 . \mathrm{BC} \\
& +0.1965 . \mathrm{C}^{2}
\end{aligned}
$$

With $Y=$ degradation rate of $\beta$-carotene, $A=$ applied ultrasonic intensity, $B=$ temperature, and $C=$ sonication time.

\subsection{Localization of maximum degradation conditions}

Fig. 6 depicts three-dimensional plots providing a graphical representation to visualize the significant relationship linking variable levels and $\beta$-carotene degradation. Each plot highlights the response behaviour as a function of two variables, with the third variable fixed to its central point. The most influent variables are the linear terms of sonication time $(C)$ and ultrasonic intensity (A) (Fig. 5). Also, a slight influence of interaction between A and $\mathrm{C}$ is observed (i.e. the presence of weak surface curvature when sonication time increases is likely responsible, Fig. 6(b) and (c)). The increase in degradation with increasing ultrasonic intensity could be due to a greater bubble residence time and the formation of larger bubbles at high energy intensities [20]. In contrast, temperature (B) has an inverse effect on $\beta$-carotene degradation, with increased degradation observed with decreasing temperature. These results could be explained by decreasing cavitation intensity with increasing temperature. The physical properties (surface tension, viscosity, and saturating vapour pressure) of solvent are the main factors affecting cavitation intensity, and the most important factor among these properties is reported to be the vapour pressure. Liquid vapour pressure has a reverse correlation with cavitation intensity, and decreases with increasing temperature [21].

The optimal conditions obtained from the first derivative of the second-order polynomial equation were derived a second time. The variables were set equal to 0 , and the equation was solved. The coded values obtained from these equations were then decoded, and optimal settings were determined as follows: $88.7 \mathrm{~W} \mathrm{~cm}^{-2}$ for ultrasonic intensity, $5{ }^{\circ} \mathrm{C}$ for temperature, and $10 \mathrm{~min}$ for sonication time (Table 4).

\subsection{Validation of the model system}

For validation of the model, $\beta$-carotene was experimentally degraded under optimal conditions, and the degradation rate was measured to $47.4 \%$. Using mathematical model, the predicted degradation rate with these conditions was $49.1 \%$ (Table 4). These results demonstrate that the experimental value is quite 
Version définitive du manuscrit publiée dans / Final version of the manuscript published in :

Ultrasonics Sonochemistry (2015), Vol. 26, p. 200-209, DOI: 10.1016/j.ultsonch.2015.04.003

Journal homepage : http://www.elsevier,com/locate/ultson

Table 3

Regression significance of coefficients for response $(Y)$. White $P$ values are significant $(<0.05)$.

\begin{tabular}{|c|c|c|c|c|c|c|c|}
\hline Factor & Coefficient & Estimate & Standard error & Df & Sum of squares & $F$ ratio & $P$ value \\
\hline Average & -4.6761 & 15.3904 & 1.24293 & & & & \\
\hline$X_{1}$ & 0.0563 & 5.77807 & 1.64931 & 1 & 113.987 & 12.27 & 0.0057 \\
\hline$X_{2}$ & 0.9928 & -2.97052 & 1.64931 & 1 & 30.127 & 3.24 & 0.1019 \\
\hline$X_{3}$ & -0.2334 & 12.7409 & 1.64931 & 1 & 554.229 & 59.68 & 0.0000 \\
\hline$X_{1} X_{1}$ & -0.0013 & -1.38757 & 1.60556 & 1 & 6.93676 & 0.75 & 0.4077 \\
\hline$X_{1} X_{2}$ & -0.00263 & -1.2775 & 2.15493 & 1 & 3.26401 & 0.35 & 0.5665 \\
\hline$X_{1} X_{3}$ & 0.0475 & 5.7175 & 2.15493 & 1 & 65.3796 & 7.04 & 0.0242 \\
\hline$X_{2} X_{2}$ & -0.0127 & -2.79826 & 1.60556 & 1 & 28.211 & 3.04 & 0.1120 \\
\hline$X_{2} X_{3}$ & -0.0801 & -4.3725 & 2.15493 & 1 & 38.2375 & 4.12 & 0.0699 \\
\hline$X_{3} X_{3}$ & 0.1965 & 2.65708 & 1.60556 & 1 & 25.4361 & 2.74 & 0.1289 \\
\hline Total error & & & & 10 & 92.8745 & & \\
\hline Total (corr.) & & & & 19 & 964.587 & & \\
\hline
\end{tabular}

Standardized Pareto Chart for dedradation of beta carotene

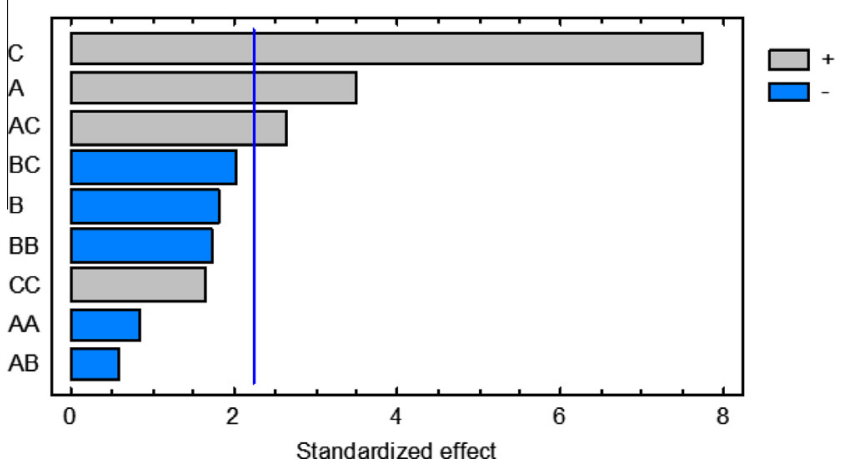

Fig. 5. Standardized Pareto chart for \% all-E- $\beta$-carotene degradation A: ultrasonic intensity; B: temperature; C: sonication time Combination of these factors are indicated by coupled letters. +: positive effect; -: negative effect.

close to the predicted value, confirming the validity and relevance of the model.

\subsection{Analysis of degradation products of $\beta$-carotene}

$\beta$-Carotene treated using the optimal loss conditions was analysed using UHPLC-DAD-MS in order to identify degradation products. In the UV-Vis chromatogram of the treated $\beta$-carotene solution, newly formed products were detected at shorter retention times than $\beta$-carotene (Fig. 7). Their analysis showed the presence of three types of compounds: $Z$-isomers of $\beta$-carotene (Fig. 7(A)), oxygenated derivatives of $\beta$-carotene (Fig. $7(B)$ ), and oxidative cleavage products with an aldehyde functional group ( $\beta$-apo-carotenals) (Fig. 7(C)).
Table 4

All-E- $\beta$-carotene degradation optimum conditions. Predicted and experimental degradation rate from response area.

\begin{tabular}{|c|c|c|c|c|}
\hline \multicolumn{3}{|c|}{ Maximum degradation rate conditions } & \multicolumn{2}{|c|}{ Degradation rate (\%) } \\
\hline $\begin{array}{l}\text { Ultrasonic } \\
\text { Intensity } \\
\left(\mathrm{W} \mathrm{cm}^{-2}\right)\end{array}$ & $\begin{array}{l}\text { Sonication } \\
\text { time (min) }\end{array}$ & $\begin{array}{l}\text { Temperature } \\
\left({ }^{\circ} \mathrm{C}\right)\end{array}$ & $\begin{array}{l}\text { Predicted } \\
\text { value (\%) }\end{array}$ & $\begin{array}{l}\text { Experimental } \\
\text { value (\%) }\end{array}$ \\
\hline 88.7 & 10 & 5 & 49.1 & 47.4 \\
\hline
\end{tabular}

\subsubsection{Z-isomers of $\beta$-carotene}

The chromatographic peaks in zone A (Fig. 7) have been tentatively identified as $\beta$-carotene $Z$-isomers (Fig. 8) due to their $\mathrm{m} / \mathrm{z}$ identical to all- $E$ - $\beta$-carotene, their spectrophotometric data (Table 5) and by comparison with literature data [22]. Mono Z-isomers of carotenoids usually keep the fine structure with three peaks of the $E$ carotenoid and present a small hypochromic shift in the highest absorbance (peak II) of 2-4 nm (peaks 8,9 and 11, Table 5), a higher shift is characteristic of a di-Z-isomer (peak 10 , Table 5). UV/visible spectra of mono $Z$-isomers present a new absorption band ( $Z$ absorbance, or B peak also called cis peak), at a characteristic position, in our case about $132-137 \mathrm{~nm}$ below the longest-wavelength absorption maximum (peak III). The intensity of this new absorption band depends on the position of the $Z$ double bond, it is greater as the $Z$ double bond is nearer to the centre of the molecule, and this new bond is not detectable in the di-Z-isomer probably because the di-Z-isomer is symmetrical [23].

$Z$-Isomers of $\beta$-carotene have been found previously in $\beta$-carotene treated with ultrasound [17]. We hypothesize that the energy provided by ultrasound has been able to produce one diradical, called a Doering's diradical [24], from all-E- $\beta$-carotene (a)

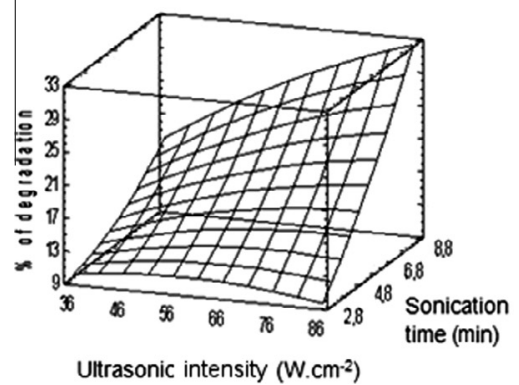

(b)

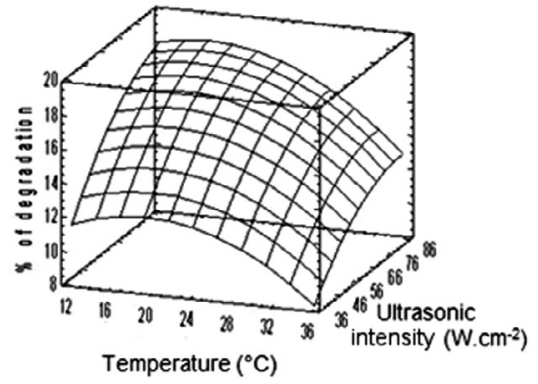

(c)

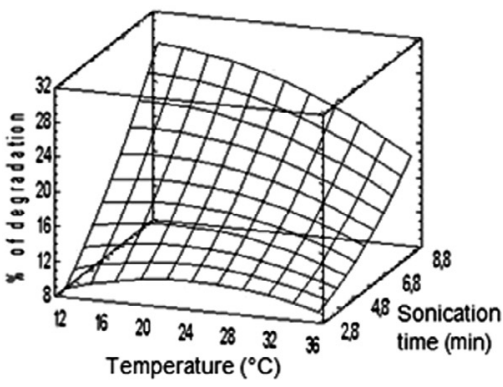

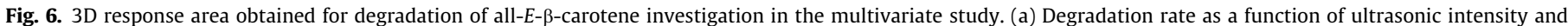

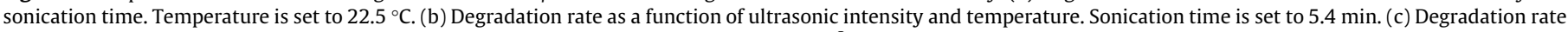
as a function of temperature and sonication time. Ultrasonic intensity is set to $49.8 \mathrm{~W} \mathrm{~cm}^{-2}$. 
Version définitive du manuscrit publiée dans / Final version of the manuscript published in :

Ultrasonics Sonochemistry (2015), Vol. 26, p. 200-209, DOI: 10.1016/j.ultsonch.2015.04.003

Journal homepage : http://www.elsevier.com/locate/ultson

(1 to 2a Fig. 9). The diradical conformation is stabilized by resonance which allows rotation around the axis of single $C^{-}-C^{\cdot}$ bond (2a to $\mathbf{2 b}$ Fig. 9). Then the diradical subsequently returns to the double bond, but under the $Z$ configuration ( $2 \mathbf{b}$ to $\mathbf{3}$ Fig. 9).

\subsubsection{Oxygenated $\beta$-carotene derivatives}

Compounds with a parent ion $m / z=553.5 \mathrm{Da}$, corresponding to $\left[M_{\beta \text {-carotene }}+16+1\right]^{+}$, were detected in positive APCI mode, suggesting the presence of a hydroxyl or an epoxy group. Moreover, the MS fragmentation spectra revealed a daughter ion at $m / z=535.3 \mathrm{Da}$, which we attributed to a water loss. UV-Vis spectra were compared with literature values for $\beta$-carotene epoxides $[25,26]$. Most of the experimentally observed peaks had no fine structure and a $\lambda_{\max }$ from $330 \mathrm{~nm}$ to $400 \mathrm{~nm}$, which do not match with previously reported epoxides, except 5,6-epoxy$\beta$-carotene, which could correspond to one of the minor peaks. We assume these products could be formed from radical species produced by ultrasound action with water (Fig. 4).

\subsection{3. $\beta$-Apo-carotenals}

After ultrasound treatment, a series of seven peaks corresponding to $\beta$-apo-carotenals, containing three to nine carbon-carbon conjugated double bonds, were tentatively identified (Fig. 10) thanks to their mass and UV-Vis spectra and by comparison with literature data $[23,25]$. Moreover, $\beta$-carotene was oxidized using potassium permanganate following the method of Caris-Veyrat et al. [27], changing lycopene with $\beta$-carotene. The resulting mixture of aldehyde derivatives was used as pseudo-standard molecules for matching retention time, parent ion mass and UV-Vis. spectra. The shortest product observed was $\beta$-apo-11carotenal (peak 1, Fig. 10) and the longest product observed was $\beta$-apo-8'-carotenal (peak 7, Fig. 10). Their retention time, parent mass ions, and UV-Vis. spectra are summarized in Table 5. The UV-Vis spectra of $\beta$-apo-carotenals no longer have a fine structure and only one absorption band is present, the longer the carbon chain conjugation of the $\beta$-apo-carotenal, the higher the $\lambda_{\max }$.

We hypothesize that the double bond cleavage is achieved through a radical mechanism involving triplet oxygen reacting on a di $Z$ diradical of the carotenoid (2b Fig. 9) to produce a dioxetane species which decomposes to give the aldehyde and ketone functions of the apo-carotenals and apo-carotenones [28,29].

\subsection{Comprehension of degradation mechanism induced by ultrasound on food products}

Although ultrasound treatments are able to produce beneficial modifications to food quality parameters such as for instance a decrease in viscosity, they can also cause some alterations. Indeed critical temperature and pressure conditions generated locally by ultrasound may generate the appearance of off-flavors like metallic taste, color changes, decrease of sugar content, and/ or modifications of the chemical structure of some constituents, effects which could be due to hydrolysis or oxidation phenomena [10] linked to the formation of radicals [30] (Fig. 11).

Table 6 summarizes few studies on the effect of ultrasounds on food products and experimental conditions. In the case of apple and cranberry juices treated by ultrasound, a darkening of samples was observed and some off-flavors were detected [31]. Thermosonication of watercress resulted in color changes as well, although the chlorophyll content did not present significant variations [32]. The sonication of tomato juice revealed also color modifications which authors related to a decrease in carotenoid

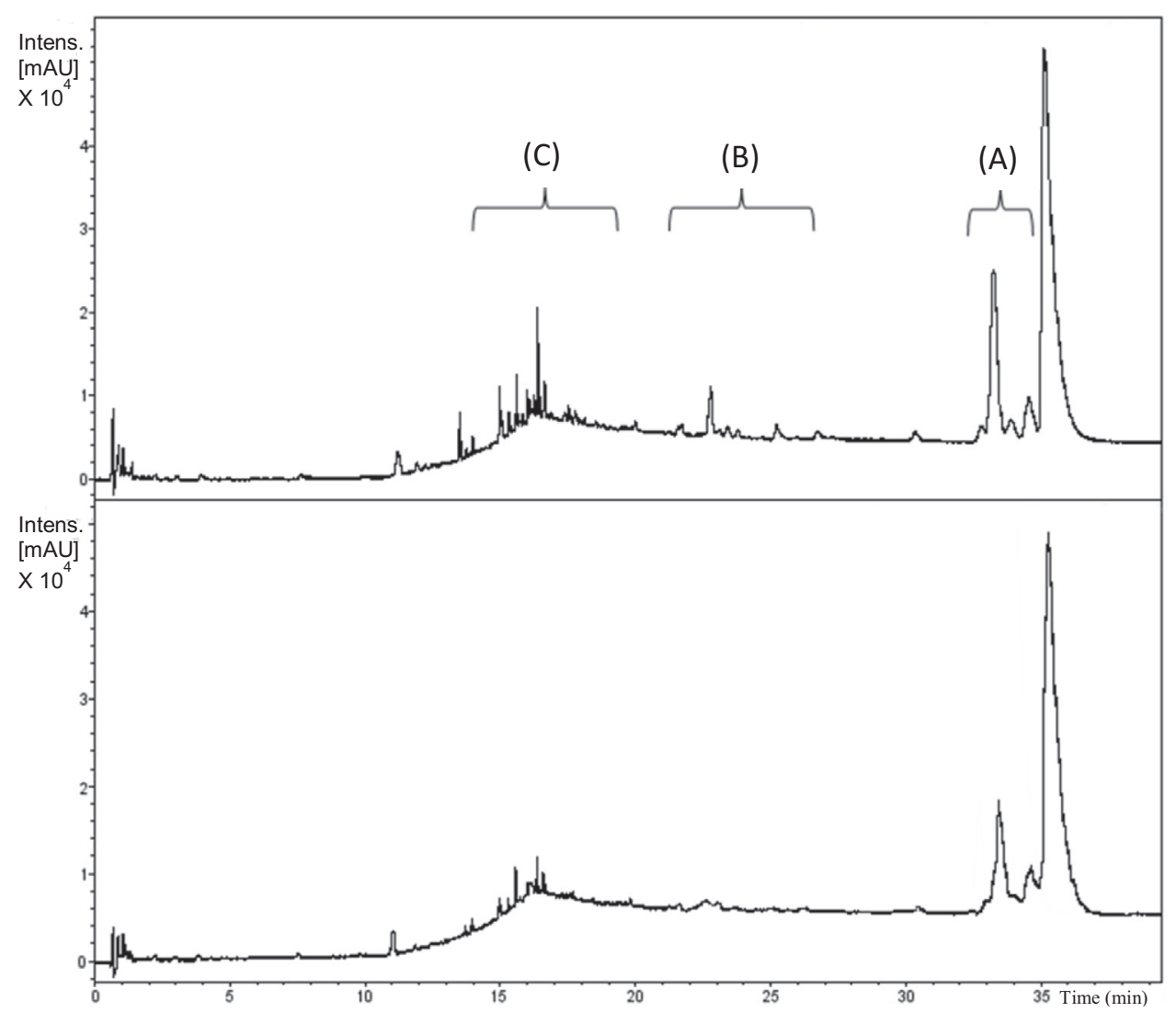

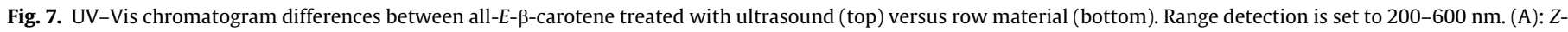
$\beta$-carotene; highest last peak corresponds to all-E- $\beta$-carotene; (B); oxygenated $\beta$-carotene derivatives; (C): $\beta$-apo-carotenals. 
Version définitive du manuscrit publiée dans / Final version of the manuscript published in :

Ultrasonics Sonochemistry (2015), Vol. 26, p. 200-209, DOI: 10.1016/j.ultsonch.2015.04.003

Journal homepage : http://www.elsevier.com/locate/ultson

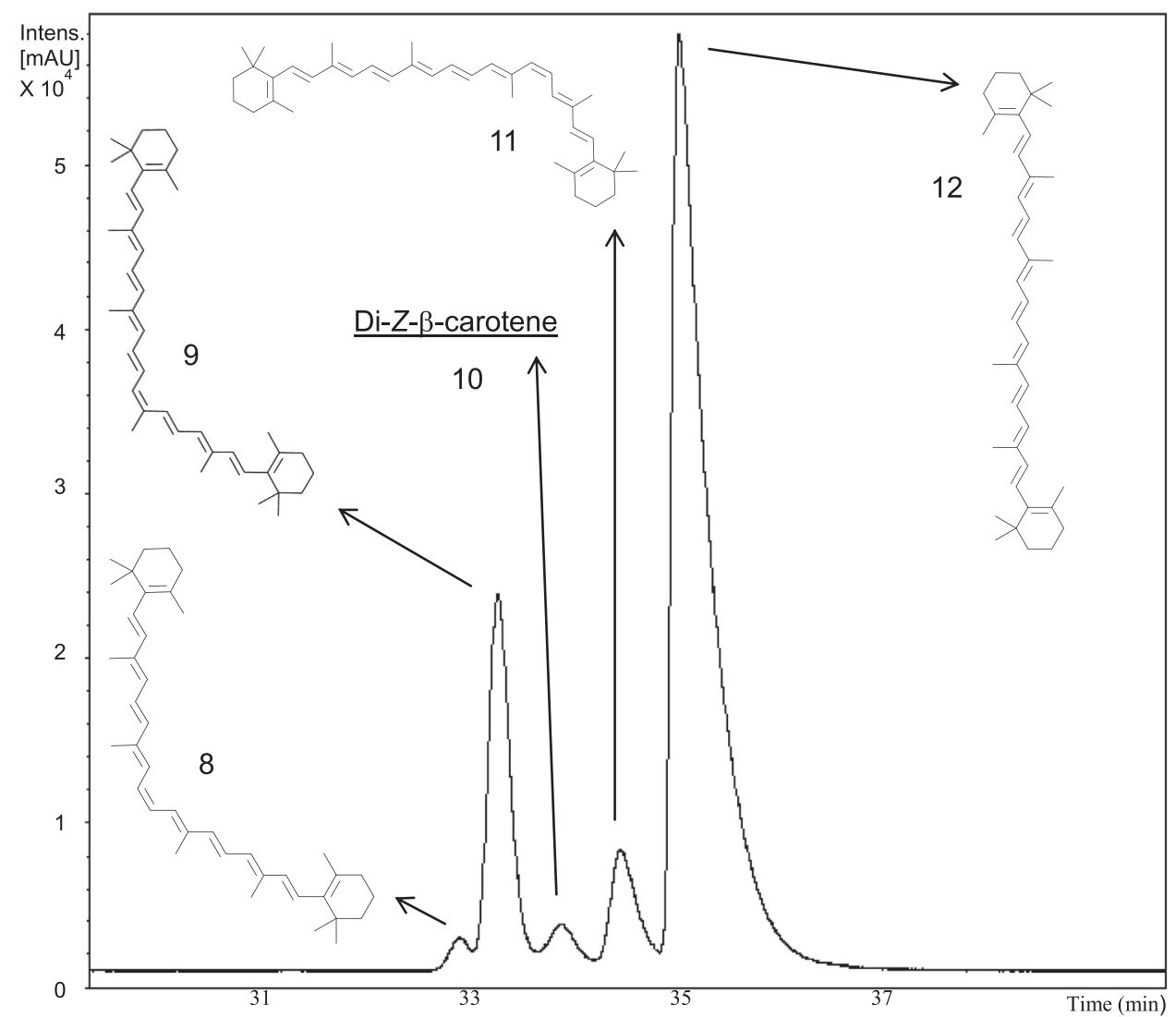

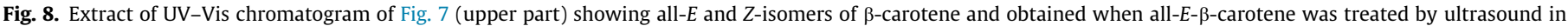
water using maximal loss parameters (sum of 445-455 nm). Numbers correspond to compounds listed in Table 5.

Table 5

Mass and spectrophotometric data of $\beta$-carotene derivatives formed after ultrasound treatment.

\begin{tabular}{|c|c|c|c|c|c|c|c|c|}
\hline Peak number & Identified compound name & Ret. time (min.) & $\begin{array}{l}Z \text { abs. } \\
\text { B peak } \lambda \mathrm{nm}\end{array}$ & $\mathrm{B} / \mathrm{II}(\%)$ & $\begin{array}{l}\text { Highest abs. } \\
\text { Peak II } \lambda \mathrm{nm}\end{array}$ & $\begin{array}{l}\text { Longest abs. } \\
\text { Peak III } \lambda \mathrm{nm}\end{array}$ & III/II (\%) & $m / z\left[\mathrm{M}+\mathrm{H}^{+}\right](\mathrm{Da})$ \\
\hline 1 & $\beta$-Apo-11-carotenal & 13.5 & - & - & 278 & - & - & 219.1 \\
\hline 2 & $\beta$-Apo-13-carotenone & 14.0 & - & - & 347 & - & - & 259.1 \\
\hline 3 & $\beta$-Apo-15-carotenal (retinal) & 14.7 & - & - & 370 & - & - & 285.2 \\
\hline 4 & $\beta$-Apo-14'-carotenal & 15.7 & - & - & 390 & - & - & 311.3 \\
\hline 5 & $\beta$-Apo- $12^{\prime}$-carotenal & 16.3 & - & - & 415 & - & - & 351.4 \\
\hline 6 & $\beta$-Apo- $10^{\prime}$-carotenal & 16.6 & - & - & 440 & - & - & 377.4 \\
\hline 7 & $\beta$-Apo-8'-carotenal & 17.6 & - & - & 454 & - & - & 417.4 \\
\hline 8 & $\beta$-Z-15-carotene & 32.9 & 340 & 64 & 453 & 477 & 2 & 537.5 \\
\hline 9 & $\beta$-Z-9-carotene & 33.1 & 344 & 16 & 449 & 476 & 20 & 537.5 \\
\hline 10 & $\beta$-Di-Z-carotene & 33.8 & - & - & 442 & 467 & 1 & 537.5 \\
\hline 11 & $\beta-Z$-13-carotene & 34.4 & 341 & 48 & 448 & 473 & 6 & 537.5 \\
\hline 12 & All-E- $\beta$-carotene & 35.1 & - & - & 455 & 482 & 25 & 537.5 \\
\hline
\end{tabular}

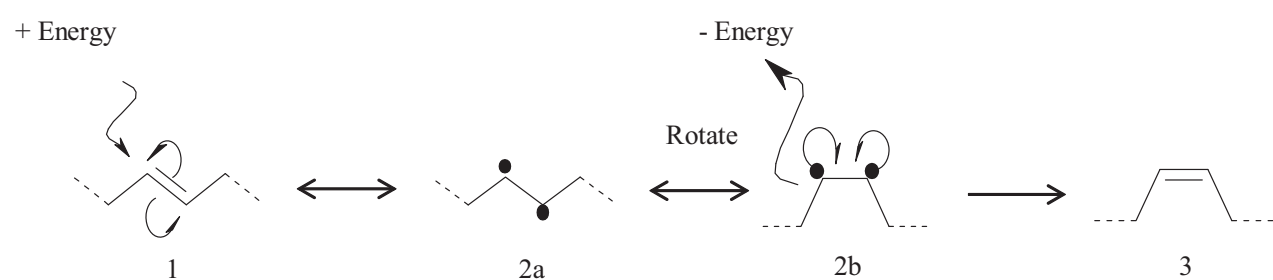

Fig. 9. Double bond isomerization through a radical mechanism: 1 : $E$ singlet state. 2a: $E$ triplet state. 2 b: $Z$ triplet state. $3: Z$ singlet state.

pigments by isomerization [33]. After sonication treatment of pineapple, grape and cranberry juices, a changing of color was also observed, due to the degradation of pigments and non-enzymatic browning [34]. By comparison with the conventional preparation of chocolate mousse, darker color was observed in ultrasoundassisted preparation due to the homogenous distribution of fat globules [35]. Non-enzymatic browning in certain products model systems was studied with a continuous sonication system and 
Version définitive du manuscrit publiée dans / Final version of the manuscript published in :

Ultrasonics Sonochemistry (2015), Vol. 26, p. 200-209, DOI: 10.1016/j.ultsonch.2015.04.003

Journal homepage : http://www.elsevier.com/locate/ultson

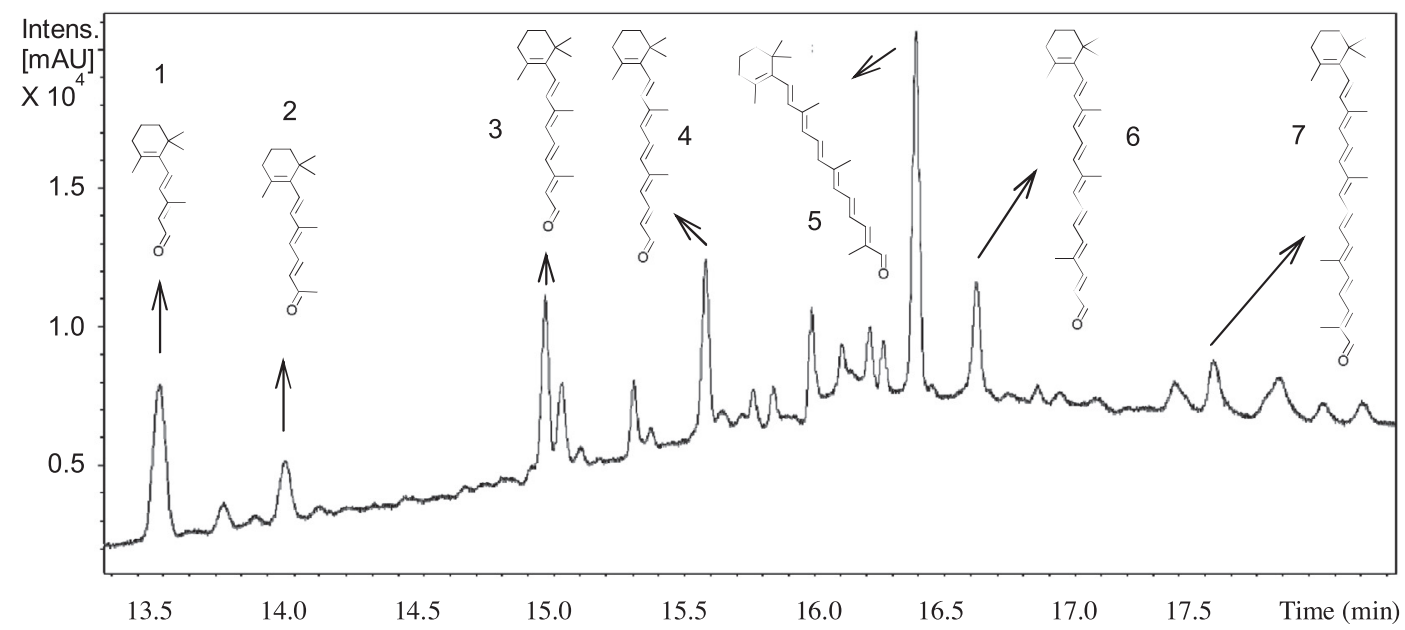

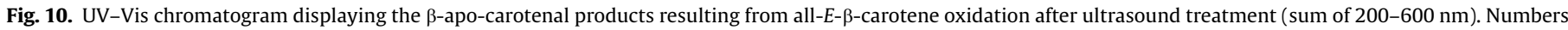
correspond to compounds listed in Table 5.

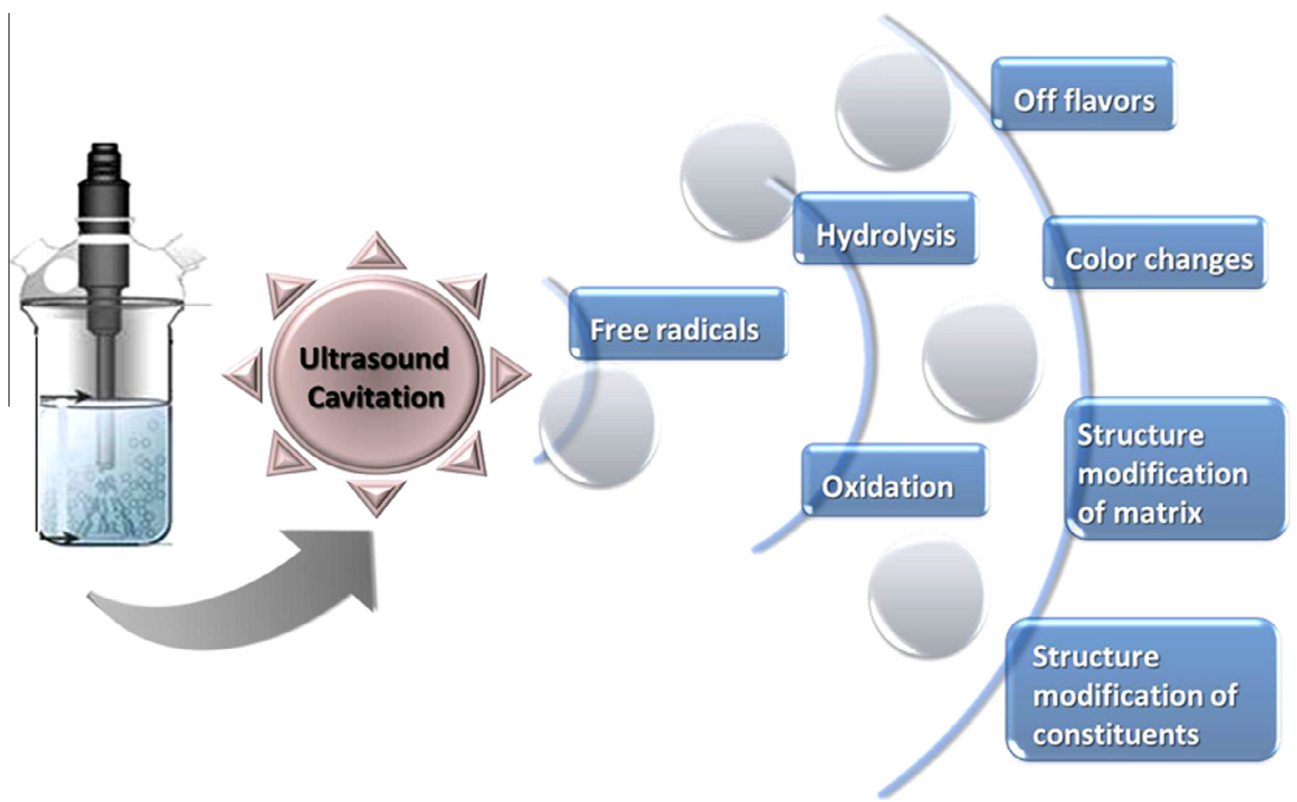

Fig. 11. Chemical effects and changes in food properties generated by ultrasound cavitation.

Table 6

Effect of ultrasound on sonicated food products

\begin{tabular}{|c|c|c|c|c|}
\hline Food matrix & Analyte & Experimental conditions & Observations & References \\
\hline $\begin{array}{l}\text { Apple and cranberry } \\
\text { juice }\end{array}$ & $\begin{array}{l}\text { Color, } \\
\text { anthocyanin }\end{array}$ & $\begin{array}{l}20 \text { A, } 750 \text { B, probe } \mathbf{C}, 8 \mathbf{D}, 43-58 \mathbf{E} \text {, color, anthocyanin } \\
\text { content } \mathbf{F} \text {, manothermosonication G }\end{array}$ & $\begin{array}{l}\text { Darkening of sonicated samples, detection of off- } \\
\text { flavors and decrease of anthocyanin content }\end{array}$ & [31] \\
\hline $\begin{array}{l}\text { Watercress } \\
\text { (Nasturtium } \\
\text { officinale) }\end{array}$ & Color & 20 A, 125 B, probe C, 0-120 D, 82-92 E, color F, blanching G & Color changes (increase of the green color) & [32] \\
\hline Tomato juice & $\begin{array}{l}\text { Color, acid } \\
\text { ascorbic }\end{array}$ & $\begin{array}{l}20 \text { A, } 1500 \text { B, probe } \mathbf{C}, 2-10 \text { D, 32-45 E, color, ascorbic acid } \\
\text { content } \mathbf{F} \text {, juice processing G }\end{array}$ & Color modifications and ascorbic acid degradation & [33] \\
\hline $\begin{array}{l}\text { Pineapple, grape and } \\
\text { cranberry juices }\end{array}$ & $\mathrm{pH}$, color & $\begin{array}{l}24 \text { A, } 400 \text { B, probe } \mathbf{C}, 0.5-10 \text { D, } 40-60 \text { E, potentiometer, } \\
\text { spectrophotometer F, microbial inactivation G }\end{array}$ & Changes in color and $\mathrm{pH}$ & [34] \\
\hline Chocolate mousse & Color, lipids & $\begin{array}{l}25 \mathbf{A}, 150 \mathbf{B} \text {, bath C, } 2 \mathbf{D}, 25 \mathbf{E} \text {, color, sensory analysis } \mathbf{F} \text {, } \\
\text { food preparation } \mathbf{G}\end{array}$ & $\begin{array}{l}\text { Darker color of sonicated samples, decrease of } \\
\text { viscosity and apparition of off-flavors }\end{array}$ & [35] \\
\hline $\begin{array}{l}\text { Orange juice } \\
\quad \text { Milk }\end{array}$ & $\begin{array}{l}\text { Ascorbic acid, } \\
\beta \text {-carotene }\end{array}$ & $\begin{array}{l}20 \text { A, - B, bath C, 0.2-0.5 D, 55-85 E, UV F, enzyme } \\
\text { inactivation G }\end{array}$ & $\begin{array}{l}\text { Decrease in ascorbic acid and } \beta \text {-carotene contents } \\
\text { Color change (brown pigments) }\end{array}$ & [36] \\
\hline
\end{tabular}

A: frequency $(\mathrm{kHz}), \mathbf{B}$ : power $(\mathrm{W})$, $\mathbf{C}$ : type of ultrasound apparatus, $\mathbf{D}$ : exposure time (min), E: temperature $\left({ }^{\circ} \mathrm{C}\right), \mathbf{F}$ : detection and analysis method, $\mathbf{G}$ : process. HPLC: high-performance liquid chromatography.

UV: ultra-violet spectroscopy. 
brown pigments in milk treated by ultrasound increased with treatment time compared to heat-treated milk, which was probably caused by the Maillard reaction [36].

\section{Conclusion}

To evaluate the extent of $\beta$-carotene degradation during ultrasound treatment, analogous to the treatment of this compound during food processing or extraction from vegetables, we have determined the main parameters affecting the stability of $\beta$-carotene and studied the formation of its derived products using a model system. $\beta$-Carotene degradation is more pronounced in aqueous system than in organic solvents. Degradation is also more pronounced under air than under argon. In aqueous medium, the CCD results reveal that applying ultrasound under atmospheric air is an efficient way to degrade $\beta$-carotene. Under these conditions, $\beta$-carotene loss is likely caused by chemical species from air and water, but also, for a large part, by mechanic-chemical effects to its conjugated polyene skeleton, providing $Z$-isomers and $\beta$-apo-carotenals. The results from CCD have demonstrated that sonication time is the most influential factor leading to $\beta$-carotene degradation, followed by ultrasonic intensity. Temperature has a less extensive and an inverse effect on the degradation rate of $\beta$-carotene, with higher temperatures resulting in less loss of $\beta$-carotene, likely due to ultrasound cavitation effects.

$\beta$-Carotene degradation products have been tentatively identified as four $Z$-isomers and seven $\beta$-apo-carotenals. Other oxygenated $\beta$-carotene derived compounds were formed with low yield and could not be conclusively identified.

Considering these results, we advise that particular attention should be taken when using ultrasound with fruits and vegetables containing carotenoids. Furthermore, additional work should be done to determine how ultrasonic processing affects $\beta$-carotene when present as part of a food matrix.

\section{Acknowledgements}

We thank Dr. Rachel Kopec for her kind help for the statistics and writing assistance.

\section{References}

[1] A.C. Soria, M. Villamiel, Effect of ultrasound on the technological properties and bioactivity of food: a review, Trends Food Sci. Technol. 21 (2010) 323-331.

[2] M.K. Khan, M. Abert-Vian, A.-S. Fabiano-Tixier, O. Dangles, F. Chemat Ultrasound-assisted extraction of polyphenols (flavanone glycosides) from orange (Citrus sinensis L.) peel, Food Chem. 119 (2010) 851-858.

[3] T.J. Mason, L. Paniwnyk, F. Chemat, M.A. Vian, Ultrasonic food processing, in: Alternatives to Conventional Food Processing, Royal Society of Chemistry, London Burlington House, Piccadilly, London W1J OBA, 2010: pp. 395-421.

[4] D. Pingret, A.-S. Fabiano-Tixier, F. Chemat, Degradation during application of ultrasound in food processing: a review, Food Control 31 (2013) 593-606.

[5] F. Chemat, Zill-e-Huma, M.K. Khan, Applications of ultrasound in food technology: processing, preservation and extraction, Ultrason. Sonochem. 18 (2011) 813-835.

[6] R.G. Earnshaw, J. Appleyard, R.M. Hurst, Understanding physical inactivation processes: combined preservation opportunities using heat, ultrasound and pressure, Int. J. Food Microbiol. 28 (1995) 197-219.

[7] M. Villamiel, P. de Jong, Influence of high-intensity ultrasound and heat treatment in continuous flow on fat, proteins, and native enzymes of milk, J. Agric. Food Chem. 48 (2000) 472-478

[8] T.J. Mason, L. Paniwnyk, J.P. Lorimer, The uses of ultrasound in food technology, Ultrason. Sonochem. 3 (1996) S253-S260.

[9] F. Chemat, I. Grondin, A. Shum Cheong Sing, J. Smadja, Deterioration of edible oils during food processing by ultrasound, Ultrason. Sonochem. 11 (2004) 13-15.
[10] D. Pingret, G. Durand, A.-S. Fabiano-Tixier, A. Rockenbauer, C. Ginies, F. Chemat, Degradation of edible oil during food processing by ultrasound: electron paramagnetic resonance, physicochemical, and sensory appreciation, J. Agric. Food Chem. 60 (2012) 7761-7768.

[11] Y. Iida, T. Tuziuti, K. Yasui, A. Towata, T. Kozuka, Control of viscosity in starch and polysaccharide solutions with ultrasound after gelatinization, Innovative Food Sci. Emerg. Technol. 9 (2008) 140-146.

[12] R. Czechowska-Biskup, B. Rokita, S. Lotfy, P. Ulanski, J.M. Rosiak, Degradation of chitosan and starch by 360-kHz ultrasound, Carbohydr. Polym. 60 (2005) 175-184.

[13] L. Paniwnyk, E. Beaufoy, J. Lorimer, T. Mason, The extraction of rutin from flower buds of Sophora japonica, Ultrason. Sonochem. 8 (2001) 299-301.

[14] L. Qiao, Y. Sun, R. Chen, Y. Fu, W. Zhang, X. Li, et al., Sonochemical effects on 14 flavonoids common in citrus: relation to stability, PLoS ONE 9 (2014) e87766.

[15] L. Qiao, X. Ye, Y. Sun, J. Ying, Y. Shen, J. Chen, Sonochemical effects on free phenolic acids under ultrasound treatment in a model system, Ultrason. Sonochem. 20 (2013) 1017-1025.

[16] L. Zhao, G. Zhao, F. Chen, Z. Wang, J. Wu, X. Hu, Different effects of microwave and ultrasound on the stability of (all-E)-astaxanthin, J. Agric. Food Chem. 54 (2006) 8346-8351.

[17] Y. Sun, G. Ma, X. Ye, Y. Kakuda, R. Meng, Stability of all-trans-ß-carotene under ultrasound treatment in a model system: effects of different factors, kinetics and newly formed compounds, Ultrason. Sonochem. 17 (2010) 654-661.

[18] I. Egea, C. Barsan, W. Bian, E. Purgatto, A. Latché, C. Chervin, et al., Chromoplast differentiation: current status and perspectives, Plant Cell Physiol. 51 (2010) $1601-1611$.

[19] L. Villeneuve, L. Alberti, J.-P. Steghens, J.-M. Lancelin, J.-L. Mestas, Assay of hydroxyl radicals generated by focused ultrasound, Ultrason. Sonochem. 16 (2009) 339-344.

[20] T.G. Leighton, What is ultrasound?, Prog Biophys. Mol. Biol. 93 (2007) 3-83.

[21] S. Hemwimol, P. Pavasant, A. Shotipruk, Ultrasound-assisted extraction of anthraquinones from roots of Morinda citrifolia, Ultrason. Sonochem. 13 (2006) 543-548.

[22] V. Böhm, N.L. Puspitasari-Nienaber, M.G. Ferruzzi, S.J. Schwartz, Trolox equivalent antioxidant capacity of different geometrical isomers of $\alpha$ carotene, $\beta$-carotene, lycopene, and zeaxanthin, J. Agric. Food Chem. 50 (2002) 221-226.

[23] G. Britton, S. Liaaen-Jensen, H. Pfander, UV/visible spectroscopy (Chapter 2), in: Carotenoids Vol 1b: Spectroscopy, 1st ed., Birkhauser Verlag, P.O.Box 133, CH-4010 Basel, Switzerland, 1995.

[24] W. von Doering, C. Sotiriou-Leventis, W.R. Roth, Thermal interconversions among 15-cis-, 13-cis-, and all-trans-.beta.-carotene: kinetics, Arrhenius parameters, thermochemistry, and potential relevance to anticarcinogenicity of all-trans-.beta.-carotene, J. Am. Chem. Soc. 117 (1995) 2747-2757.

[25] G. Britton, S. Liaaen-Jensen, H. Pfander, Carotenoids: Handbook, illustrated edition, Birkhauser Verlag, P.O.Box 133, CH-4010 Basel, Switzerland, 2004.

[26] E.B. Rodriguez, D.B. Rodriguez-Amaya, Formation of apocarotenals and epoxycarotenoids from [beta]-carotene by chemical reactions and by autoxidation in model systems and processed foods, Food Chem. 101 (2007) 563-572.

[27] C. Caris-Veyrat, A. Schmid, M. Carail, V. Bohm, Cleavage products of lycopene produced by in vitro oxidations: characterization and mechanisms of formation, J. Agric. Food Chem. 51 (2003) 7318-7325.

[28] R.C. Mordi, J.C. Walton, G.W. Burton, L. Hughes, I.U. Keith, L.A. David, et al., Oxidative degradation of $\beta$-carotene and $\beta$-apo- $8^{\prime}$-carotenal, Tetrahedron 49 (1993) 911-928.

[29] R.C. Mordi, Mechanism of beta-carotene degradation, Biochem. J. 292 (1993) $310-312$.

[30] P. Riesz, D. Berdahl, C.L. Christman, Free radical generation by ultrasound in aqueous and nonaqueous solutions, Environ. Health Perspect. 64 (1985) 233252.

[31] I.M. Caminiti, F. Noci, A. Muñoz, P. Whyte, D.J. Morgan, D.A. Cronin, et al., Impact of selected combinations of non-thermal processing technologies on the quality of an apple and cranberry juice blend, Food Chem. 124 (2011) 1387-1392.

[32] R.M.S. Cruz, M.C. Vieira, C.L.M. Silva, Modelling kinetics of watercress (Nasturtium officinale) colour changes due to heat and thermosonication treatments, Innovative Food Sci. Emerg. Technol. 8 (2007) 244-252.

[33] A.O. Adekunte, B.K. Tiwari, P.J. Cullen, A.G.M. Scannell, C.P. O’Donnell, Effect of sonication on colour, ascorbic acid and yeast inactivation in tomato juice, Food Chem. 122 (2010) 500-507.

[34] D. Bermúdez-Aguirre, G.V. Barbosa-Cánovas, Inactivation of Saccharomyces cerevisiae in pineapple, grape and cranberry juices under pulsed and continuous thermo-sonication treatments, J. Food Eng. 108 (2012) 383-392.

[35] D. Pingret, A.-S. Fabiano-Tixier, E. Petitcolas, J.-P. Canselier, F. Chemat, First investigation on ultrasound-assisted preparation of food products: sensory and physicochemical characteristics, J. Food Sci. 76 (2011) C287-C292.

[36] A. Vercet, J. Burgos, P. López-Buesa, Manothermosonication of foods and foodresembling systems: effect on nutrient content and nonenzymatic browning, J. Agric. Food Chem. 49 (2001) 483-489. 